\title{
A novel fragment derived from the $\beta$ chain of human fibrinogen, $\beta 43-63$, is a potent inhibitor of activated endothelial cells in vitro and in vivo
}

\author{
E Krajewska', CE Lewis', Y-Y Chen', A Welford ',2, S Tazzyman' and CA Staton*,3 \\ 'Tumor Targeting Group, University of Sheffield Medical School, Sheffield SIO 2RX, UK; ${ }^{2}$ Tumour Microcirculation Group, University of Sheffield \\ Medical School, Sheffield SIO 2RX, UK; ${ }^{3}$ Microcirculation Research Group, University of Sheffield Medical School, Sheffield SIO 2RX, UK
}

BACKGROUND: Angiogenesis and haemostasis are closely linked within tumours with many haemostatic proteins regulating tumour angiogenesis. Indeed we previously identified a fragment of human fibrinogen, fibrinogen E-fragment (FgnE) with potent antiangiogenic properties in vitro and cytotoxic effects on tumour vessels in vivo. We therefore investigated which region of FgnE was mediating vessel cytotoxicity.

METHODS: Human dermal microvascular endothelial cells (ECs) were used to test the efficacy of peptides derived from FgnE on proliferation, migration, differentiation, apoptosis and adhesion before testing the efficacy of an active peptide on tumour vasculature in vivo.

RESULTS: We identified a 20-amino-acid peptide derived from the $\beta$ chain of FgnE, $\beta 43-63$, which had no effect on EC proliferation or migration but markedly inhibited the ability of activated ECs to form tubules or to adhere to various constituents of the extracellular matrix - collagen IV, fibronectin and vitronectin. Furthermore, our data show that $\beta 43-63$ interacts with ECs, in part, by binding to $\alpha_{v} \beta_{3}$, so soluble $\alpha_{v} \beta_{3}$ abrogated $\beta 43-63$ inhibition of tubule formation by activated ECs. Finally, when injected into mice bearing tumour xenografts, $\beta 43-63$ inhibited tumour vascularisation and induced formation of significant tumour necrosis.

CONCLUSIONS: Taken together, these data suggest that $\beta 43-63$ is a novel anti-tumour peptide whose anti-angiogenic effects are mediated by $\alpha_{\mathrm{v}} \beta_{3}$.

British Journal of Cancer (2010) I 02, 594-601. doi:10.1038/sj.bjc.6605495 www.bjcancer.com

Published online 12 January 2010

(C) 2010 Cancer Research UK

Keywords: fibrinogen; $\beta 43-63$; endothelial; anti-angiogenic; haemostasis

\begin{abstract}
Angiogenesis, the outgrowth of new capillaries from the existing vasculature, is a multistep process that involves cell proliferation, migration and differentiation (Folkman, 1995). It is a critical step in tumour growth and is tightly regulated by a change in balance between pro-angiogenic and anti-angiogenic factors in the local environment. This often involves an upregulation in the expression of pro-angiogenic factors, such as vascular endothelial growth factor (VEGF), epidermal growth factor (EGF), platelet-derived growth factor (PDGF) and type II fibroblast growth factor (FGF2) (Folkman, 1995).

Many peptides derived from proteins involved in haemostasis have been shown to regulate tumour angiogenesis (Daly et al, 2003). The blood clotting factor, fibrinogen (Fgn), is a large $(340 \mathrm{kDa})$ protein that contains three pairs of nonidentical peptides: the $\alpha-, \beta$ - and $\gamma$ chains. These are arranged into three domains, the two outer D-domains and a central E-domain (Doolittle, 1981). Fibrinogen often accumulates in and around
\end{abstract}

*Correspondence: Dr CA Staton, Academic Unit of Surgical Oncology, University of Sheffield Medical School, Beech Hill Road, Sheffield SIO 2JF, UK; E-mail: c.a.staton@sheffield.ac.uk

Revised 4 November 2009; accepted 20 November 2009; published online 12 January 2010 leaky blood vessels in tumours and promotes tumour angiogenesis by supporting cell adhesion, migration, proliferation and differentiation of activated endothelial cells (ECs) (Zacharski et al, 1986). Fibrinogen can be digested in the body by plasmin and when this occurs each Fgn molecule gives rise to two D fragments, a number of small fragments, including a small peptide, $\beta 1-42$ (the $\mathrm{N}$ terminus of the $\beta$-chain) and one $50-\mathrm{kDa}$ E-fragment (called fibrinogen E-fragment; FgnE) consisting of the N-terminal regions of the $\alpha, \beta$ and $\gamma$ chains held together by disulphide bonds (Bootle-Wilbraham et al, 2000).

We previously reported that FgnE is a potent anti-angiogenic factor in vitro and vascular-damaging agent in vivo. It inhibits the migration and differentiation of human ECs in response to VEGF, EGF and FGF2 in vitro (Bootle-Wilbraham et al, 2000) and is cytotoxic for activated ECs in vitro. These effects may explain why FgnE selectively disrupts tumour endothelium, causing widespread intravascular thrombosis and tumour necrosis in vivo (Brown et al, 2002). We also showed that alphastatin, a 24-amino-acid peptide fragment derived from the $\mathrm{N}$ terminus of the $\alpha$ chain of FgnE, mimics many of the anti-angiogenic effects of FgnE in vitro as well as its anti-vascular effects in vivo. However, it is not cytotoxic for activated EC unlike FgnE (Staton et al, 2004). 
A $\quad \mathrm{NH}_{2} \alpha$-chain
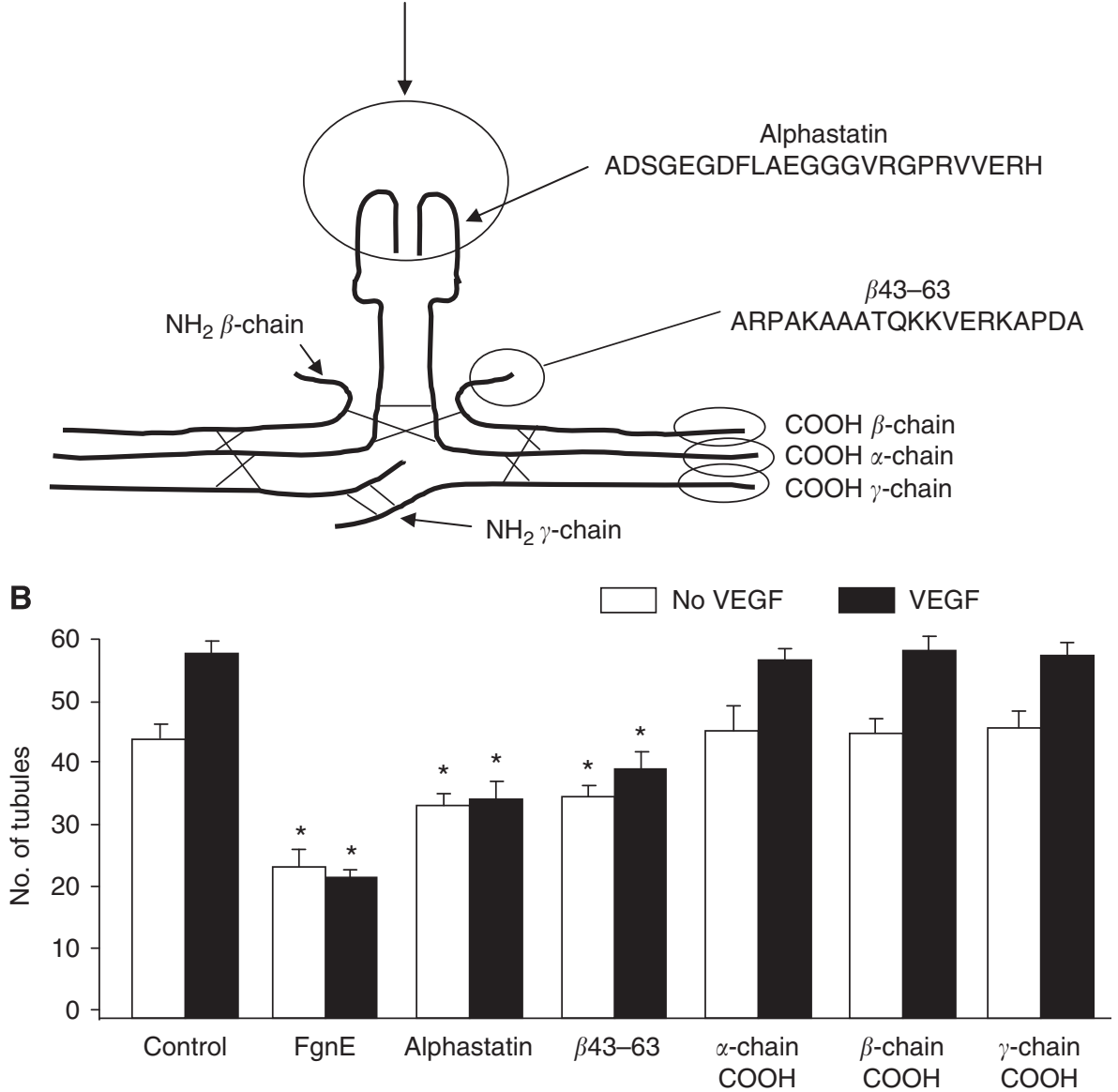

Figure I (A) Schematic illustration of FgnE. Fibrinogen consists of two $\alpha$ chains, two $\beta$ chains and two $\gamma$ chains. Alphastatin is the first 24 amino acids of the $\mathrm{N}$ terminus of the $\alpha$ chains $(\alpha \mid-24)$ whereas $\beta 43-63$ is the first 20 amino acids on the $\mathrm{N}$ terminus of the two $\beta$ chains. 20 -amino-acid peptides were

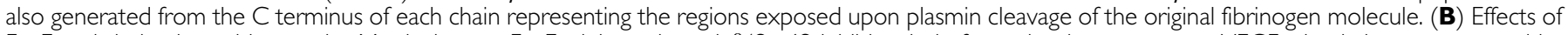
FonE and derived peptides on the Matrigel assay. FgnE, alphastatin and $\beta 43-63$ inhibit tubule formation in response to VEGF stimulation as measured by number of tubules per field of view. FgnE was used at I $\mu \mathrm{M}$, but the peptides were used at $2 \mu \mathrm{M}$ as two copies of these peptides are present in a single FgnE molecule. Data are presented as mean \pm s.e.m. $* P<0.05$ with respect to relevant control.

We show here that another peptide found in the $\mathrm{N}$ terminus of the $\beta$ chain of FgnE (amino acids 43-63, Figure 1A) also has minimal effects on EC viability but displays a pronounced ability to inhibit the adherence of activated ECs to various components of the extracellular matrix (ECM). Furthermore, we show that it does so by binding to, and blocking ECM binding of, the integrin $\alpha_{\mathrm{v}} \beta_{3}$ on ECs. Moreover, when injected into tumour-bearing mice, this peptide inhibited tumour vascularisation and caused increased levels of tumour necrosis.

\section{MATERIALS AND METHODS}

\section{Cells}

Adult human dermal microvascular endothelial cells (HuDMECs) were obtained commercially (PromoCell, Heidelberg, Germany) and cultured in microvascular endothelial cell growth medium (EGM) with supplements (consisting of $0.4 \%$ CGS/H, $5 \%$ fetal calf serum (FCS), $10 \mathrm{ng} \mathrm{ml}^{-1} \mathrm{EGF}, 1 \mu \mathrm{g} \mathrm{ml}^{-1}$ hydrocortisone, $50 \mathrm{ng} \mathrm{ml}^{-1}$ amphotericin $\mathrm{B}, 50 \mu \mathrm{g} \mathrm{ml}^{-1}$ gentamicin). Cells were grown at $37^{\circ} \mathrm{C}$ in a $100 \%$ humidified incubator with the gas phase of $5 \% \mathrm{CO}_{2}$ and routinely screened for Mycoplasma. Human dermal microvascular endothelial cells were used in the experiments until they reached passage 6 .

\section{Proteins and peptides}

All chemicals and reagents used were obtained from Sigma-Aldrich (Dorset, UK) unless stated otherwise, and were of AnalaR or highperformance liquid chromatography grade. Recombinant human growth factors (VEGF165, EGF, PDGF, HGF and FGF2) were purchased from R\&D systems (Abingdon, UK), commercial human FgnE and recombinant human $\alpha_{\mathrm{v}} \beta_{3}$ were purchased from Calbiochem (Merck, Darmstadt, Germany). $\beta 43-63$ (ARPAKAAATQKKVERKAPDA), the control peptide, a scrambled form of $\beta 43-63$ (scrambled control peptide ( $\beta$ SC): RAQVPPAKKDAARATKAKAE) and other peptides derived from FgnE, including alphastatin, were synthesised by GenScript Corporation (Piscataway, NJ, USA). In all experiments, FgnE was used at a final concentration of $1 \mu \mathrm{M}$ and the peptides used at $2 \mu \mathrm{M}$ (which corresponds to $1 \mu \mathrm{M}$ FgnE).

\section{Tubule formation assay}

A total of 96-well plates were coated with $34 \mu \mathrm{l}$ per well of growth factor-reduced (GF-reduced) Matrigel (BD Biosciences, Bedford, MA, USA). Human dermal microvascular endothelial cells were serum depleted overnight in EGM $+1 \%$ FCS and then seeded at $1.5 \times 10^{4}$ cells per well and allowed to attach for $45 \mathrm{~min}$. The medium was then replaced with treatment medium 
$(\mathrm{EGM}+1 \% \mathrm{FCS})$, with/without peptides and/or GFs: VEGF $\left(10 \mathrm{ng} \mathrm{ml}^{-1}\right)$, EGF $\left(35 \mathrm{ng} \mathrm{ml}^{-1}\right), \quad$ FGF2 $\left(25 \mathrm{ng} \mathrm{ml}^{-1}\right)$, PDGF-BB $\left(25 \mathrm{ng} \mathrm{ml}^{-1}\right)$ and hepatocyte growth factor (HGF; $100 \mathrm{ng} \mathrm{ml}^{-1}$ ). Endothelial cells on this matrix migrated and formed tubules within $6 \mathrm{~h}$ of plating (Kleinman et al, 1986). Tubule formation was monitored at $\times 40$ magnification, using a light microscope (Nikon Eclipse TS100, KingsTon upon Thames, Surrey, UK) and analysed using the image analysis package, Scion Image (Frederick, MA, USA) as previously described (Bootle-Wilbraham et al, 2000). For the experiments using $\alpha_{v} \beta_{3}$, the $\beta 43-63$ was incubated with recombinant $\alpha_{\mathrm{v}} \beta_{3}$ for $1 \mathrm{~h}$ before addition to the Matrigel assay.

\section{Migration assay}

The migration assay, adapted from Malinda et al (1999) involved the use of a 48 -well microchemotaxis chamber (Neuro Probe, Cabin John, MD, USA) with $8 \mu \mathrm{m}$ pore size polycarbonate membranes (Neuro Probe) coated with $100 \mu \mathrm{g} \mathrm{ml}^{-1}$ human collagen type I or IV. Vascular endothelial growth factor alone $\left(10 \mathrm{ng} \mathrm{ml}^{-1}\right)$ or with peptides/FgnE was dissolved in EGM $+1 \%$ FCS and placed in the bottom wells. The membrane was then positioned and $50 \mu \mathrm{l}$ of $2.5 \times 10^{5}$ HuDMECs per $\mathrm{ml}$ (serum depleted in $\mathrm{EGM}+1 \% \mathrm{FCS}$ overnight) was added to the top chamber. The chambers were incubated at $37^{\circ} \mathrm{C}$ for $4.5 \mathrm{~h}$ then migrated cells on the bottom surface were fixed and stained with Hema 'Gurr' rapid staining kit (VWR, Poole, UK) and counted at $\times 40$ magnification in three random fields per well in three replicate wells and repeated three times.

\section{Proliferation assay}

To assess proliferation of HuDMECs, we used the BrdU assay (Merck, Calbiochem, Beeston, UK), whereby BrdU is incorporated into newly synthesised DNA strands of newly proliferating cells. Human dermal microvascular endothelial cells were seeded into 96-well plates at $5 \times 10^{3}$ cells per well in EGM with $1 \%$ fetal bovine serum and then incubated with FgnE and peptides for $24 \mathrm{~h}$ as above. BrdU label was added for $6 \mathrm{~h}$ and then cells were permeabilised and incubated with antibodies according to manufacturers' instructions. The absorbance was read at $450 \mathrm{~nm}$, using an Anthos Labtec Instruments (Salzburg, Austria) plate reader.

\section{Cell viability assays}

Human dermal microvascular endothelial cells were seeded into a 48 -well plate at a density of $2 \times 10^{5}$ cells per well and then serum starved for $24 \mathrm{~h}$ in EGM $+1 \%$ FCS. The cells were then incubated for $24 \mathrm{~h}$ with $\beta 43-63$ or $\beta$ SC before a 20 -min incubation with $1 \mu \mathrm{l}$ of fluorescein isothiocyanate (FITC)-conjugated Z-VAD-FMK (carbobenzoxy-valyl-alanyl-aspartyl-fluoromethylketone; Promega, Southampton, UK), a cell permeable, irreversible pan-caspase inhibitor that allows in situ labelling of activated caspases. The cells were then washed $3 \times$ with FACS buffer (phosphate-buffered saline (PBS) with $0.1 \%$ BSA), trypsynised and finally $1 \mu \mathrm{l}$ propidium iodide (PI, $50 \mu \mathrm{g} \mathrm{ml}^{-1}$ ) was added to measure dead cells. A total of 10000 cells were analysed using FACScan (FL1 and FL2 filters - 530 and $585 \mathrm{~nm}$ ). The distribution of live, apoptotic and late apoptotic/necrotic cells were analysed based on distribution of staurosporine-treated $(400 \mathrm{nM}, 2 \mathrm{~h})$ cells that were used as the positive control for apoptosis/necrosis. Live cells had no stain at all, early apoptosis cells were stained with FITC stain only, latestage apoptotic cells with FITC and PI.

\section{Western blotting for phosphorylated Akt}

Human dermal microvascular endothelial cells were plated down into six-well plates and grown to near confluence before serum depletion (EGM $+1 \% \mathrm{FCS})$ overnight. The cells were then incubated with peptides for $3 \mathrm{~h}$ before a 5-min incubation with VEGF $\left(10 \mathrm{ng} \mathrm{ml}^{-1}\right)$. After treatment the cells were washed twice in PBS and suspended in a triple cell lysis buffer ( $50 \mathrm{~nm}$ Tris-HCI ( $\mathrm{pH} 8.5)$, $150 \mathrm{~nm} \mathrm{NaCl}, 0.1 \%$ SDS, $1 \%$ nonident-P40, $0.5 \%$ sodium deoxycholate and a complete protease inhibitor tablet (Roche, Mannheim, Germany)) and placed on ice for $20 \mathrm{~min}$ before centrifugation. Protein concentrations of the supernatants were determined using the bicinchoninic acid assay. Equal amounts of protein extracts $(20 \mu \mathrm{g})$ were separated by SDS - polyacrylamide gel electrophoresis, electrotransferred to nitrocellulose membranes and exposed to anti-Akt or phospho-Akt (BD Biosciences). Immunoreactive bands were detected by enhanced chemiluminescence (Amersham, Little Chalfont, Buckinghamshire, UK), and band intensity quantified using densitometry software (Bio-Rad, Hemel Hempstead, Hertfordshire, UK).

\section{Cell adhesion assay}

A total of 96-well plates were coated overnight with $10 \mu \mathrm{g} \mathrm{ml}^{-1}$ human collagen type IV (Sigma-Aldrich), $5 \mu \mathrm{g} \mathrm{ml}^{-1}$ human fibronectin (Merck) or $0.5 \mu \mathrm{g} \mathrm{ml}^{-1}$ human vitronectin (Invitrogen, Paisley, Renfrewshire, UK), then washed with PBS. Meanwhile, HuDMECs were serum depleted in EGM $+1 \%$ FCS overnight then lifted using non-enzymatic cell dissociation solution, and incubated for an hour at $37^{\circ} \mathrm{C}$ with VEGF $\left(10 \mathrm{ng} \mathrm{ml}^{-1}\right)$ in the absence or presence of FgnE, alphastatin, $\beta 43-63$ or $\beta$ SC. Matrix-coated 96well plates were seeded with $100 \mu \mathrm{l}$ of cell suspension (5000 cells per well) together with noncoated plates (referred to as 'plastic control'). After $1 \mathrm{~h}$ incubation at $37^{\circ} \mathrm{C}$ the wells were washed twice with PBS, and any cells that remained attached were fixed with methanol and stained with methyl blue. Stained cells were photographed (at $\times 40$ magnification) and counted in three different fields of view per well.

As integrins mediate cell adhesion to ECM proteins - and the only integrin known to mediate adhesion to all three ECM proteins studied is $\alpha_{\mathrm{v}} \beta_{3}$ - the role of this integrin in mediating the inhibiting effect of $\beta 43-63$ on ECs was investigated. Moreover, the $\beta$ chain of Fgn is thought to bind to heparin sulphate proteoglycans so the effect of heparin on cell adhesion was also investigated. 96-well plates were coated with $100 \mu \mathrm{l}$ of $\beta 43-63$ or $\beta \mathrm{SC}$ overnight $\left(10 \mu \mathrm{g} \mathrm{ml}^{-1}\right)$, then washed and pre-incubated for $1 \mathrm{~h}$ with or without recombinant $\alpha_{\mathrm{v}} \beta_{3}$ or heparin before addition of the HuDMECs (pre-incubated with VEGF). The cells were allowed to adhere for $1 \mathrm{~h}$ before washing and staining as before.

\section{Direct binding assays}

96-well plates were coated overnight with PBS (plastic control) $10 \mu \mathrm{g} \mathrm{ml}^{-1} \beta 43-63,10 \mu \mathrm{g} / \mathrm{ml} \beta \mathrm{SC}$ (negative control) or $0.5 \mu \mathrm{g} \mathrm{ml}^{-1}$ vitronectin (positive control), then washed and blocked with $5 \%$ BSA in PBS for $1 \mathrm{~h}$. The wells were then washed, incubated with recombinant $\alpha_{\mathrm{v}} \beta_{3}$ for $1.5 \mathrm{~h}$, then washed and incubated with anti$\alpha_{\mathrm{v}} \beta_{3}$ antibody for $1.5 \mathrm{~h}$, then washed and incubated with antimouse-HRP-conjugated secondary antibody for a further hour and finally washed and incubated with OPD for $15 \mathrm{~min}$ before reading on an ELISA plate reader $(450 \mathrm{~nm})$. Controls included wells coated and treated with everything except $\alpha_{\mathrm{v}} \beta_{3}$ (data shown) and nonspecific binding to plastic was subtracted from the final results.

\section{Tumour xenograft studies}

All experiments were performed under $\mathrm{HO}$ Project Licence Number PPL40/3110 and conformed to the United Kingdom Coordinating Committee on Cancer Research Guidelines for the Welfare of Animals in Experimental Neoplasia. The CaNT murine mammary adenocarcinoma is a transplanted tumour model, derived from a spontaneous tumour and is maintained in vivo 


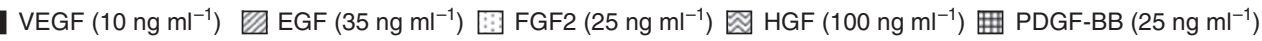
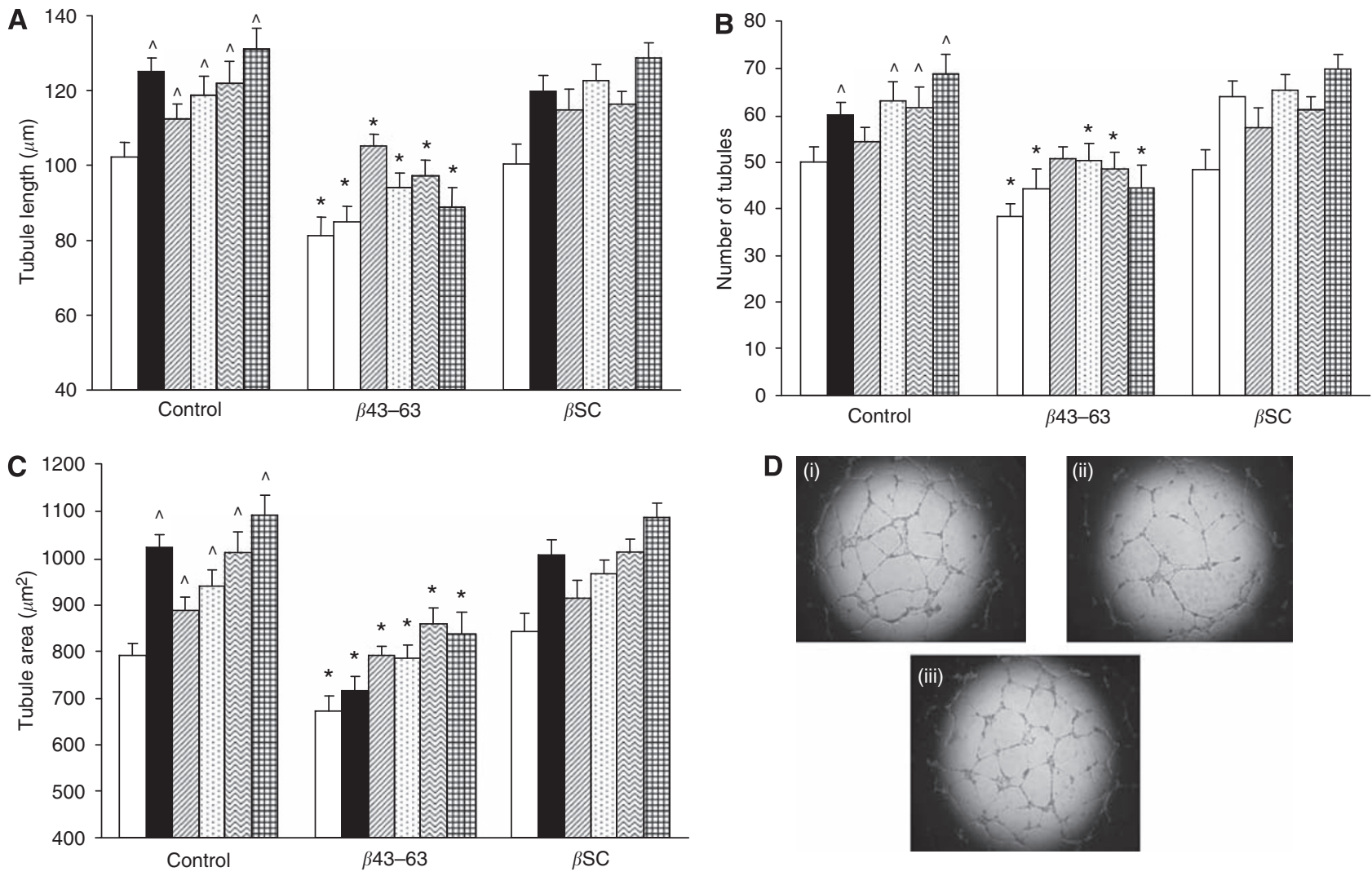

Figure $2 \beta 43-63$ also inhibits tubule formation by ECs in response to four other pro-angiogenic growth factors, PDGF, FGF2, EGF and HGF, in vitro. (A) Length, (B) number and $(\mathbf{C})$ area covered by tubules formed by HuDMECs in response to the above growth factors in the absence or presence of $\beta 43-63$ or scrambled $\beta 43-63(\beta S C)$ used at $2 \mu \mathrm{M}$. $* P<0.05$ with respect to relevant control group, $\wedge p<0.05$ with respect to control No-GF group. All data are means \pm s.e.m. Data are representative of three replicate experiments. (D) Typical appearance of VEGF-induced tubules (in wells of a 96 -well plate) in the presence of (i) VEGF alone, (ii) VEGF $+2 \mu \mathrm{m} \beta 43-63$ and (iii) VEGF $+2 \mu \mathrm{M} \beta \mathrm{SC}$.

by the transfer of tumour cells between mice (Collingridge and Chaplin, 2001). CBA/Gy mice (Gray cancer Institute, Northwood, UK) were anaesthetised by isofluorane inhalation and inoculated subcutaneously with $10^{6}$ viable CaNT tumour cells. Tumour volume was determined at regular intervals by caliper measurement (accurate to $0.1 \mathrm{~mm}$ ) in two dimensions as described previously (Brown et $a l, 2002)$ using the equation: volume $=\left(a^{2} \times b\right) / 2$, where $a$ is the smaller and $b$ the larger diameter of the two. When tumours had grown to $100-150 \mathrm{~mm}^{3}$, mice were injected i.p. daily for 10 days with $\beta 43-63\left(0.084 \mathrm{mg} \mathrm{kg}^{-1}\right)$ or vehicle (PBS).

After 10 days, mice were killed and tumours (and various normal tissues) excised, divided into two halves and fixed in either (1) $10 \%$ neutral buffered formalin or (2) zinc-based fixative (Beckstead, 1994), then processed into paraffin wax. Formalinfixed sections were stained for $\mathrm{H} \& \mathrm{E}$ and tumour necrosis assessed semi-quantitatively using a Chalkley grid method (\% necrosis) (Brown et al, 2002). Zinc-fixed sections were exposed to a rat monoclonal anti-murine CD31 (1:100; Pharmingen, San Diego, CA, USA) specific for ECs, for $60 \mathrm{~min}$ at room temperature, and immunoreactivity detected using the $\mathrm{ABC}$ rat elite kit (Vector Laboratories, UK) and diaminobenzidine. Vessels were then counted per field of view $(\times 40)$ for all tumours.

\section{Statistical analysis}

All experiments were performed at least three times, and data were analysed using the Mann-Whitney $U$-test, a nonparametric test that does not assume a Gaussian distribution in the data being analysed. $P \leqslant 0.05$ was taken as significant.

\section{RESULTS}

Our previous experiments showed that $1 \mu \mathrm{M}$ FgnE inhibited differentiation of ECs into tubule-like structures when plated on Matrigel in the presence or absence of VEGF. In contrast the parent Fgn molecule did not cause inhibition (Bootle-Wilbraham et al, 2000). We therefore initially synthesised peptides derived from the termini of the FgnE chains exposed by plasmin cleavage (Figure 1A) for testing in the Matrigel assay (Figure 1B). Of the four peptides tested, only $\beta 43-63$ inhibited EC differentiation and was therefore subjected to more thorough investigation.

Indeed Figure 2 shows that $\beta 43-63$, but not the control peptide (scrambled $\beta 43-63)$, significantly $(P<0.05)$ inhibited the length, number and area of tubules formed by EC activated by the five prominent angiogenic factors found in tumours (VEGF, PDGF-BB, EGF, FGF2 and HGF) on GF-reduced Matrigel, although $\beta 43-63$ showed only minimal inhibition of EGF-induced tubule formation. The inhibitory effects of $\beta 43-63$ were seen for both GF and nonGF activated cells. At first this may appear to suggest that ECs do not need to be 'activated' by a stimulant like VEGF to respond to these two agents. However, GF-reduced Matrigel does itself act as a stimulant/activator inducing ECs to form tubules in the absence of exogenous GFs.

Our previous experiments have shown that $1 \mu \mathrm{M}$ FgnE (the parent molecule of $\beta 43-63)$ is cytotoxic for GF-activated ECs (Bootle-Wilbraham et al, 2000). We therefore wished to ascertain whether the inhibitory effects of $\beta 43-63$ on tubule formation was due to a similar cytotoxic effect in culture. Figure $3 \mathrm{~A}$ shows that $\beta 43-63$ slightly abrogated the pro-survival effect of VEGF on ECs, 

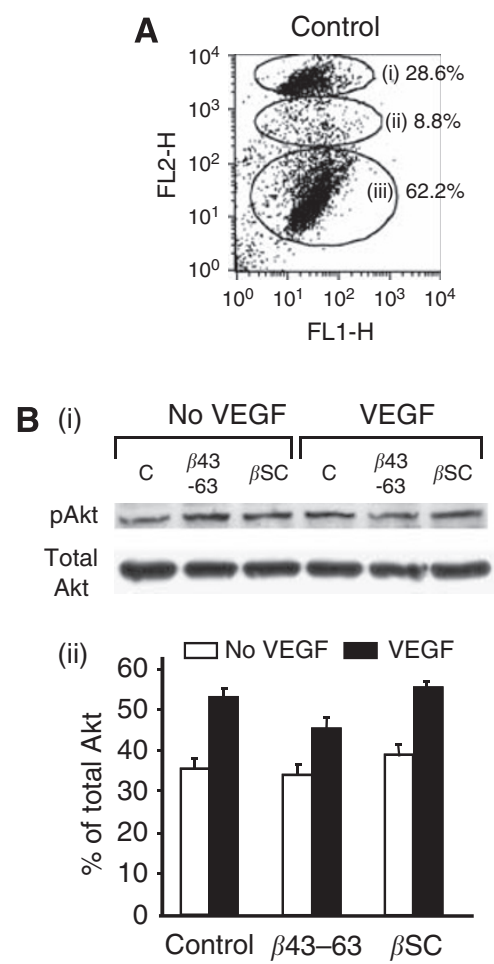

$\beta 43-63$

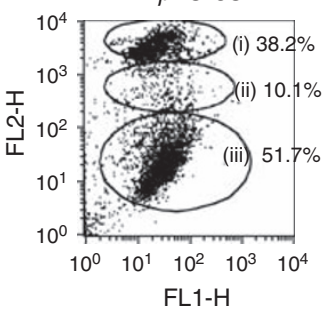

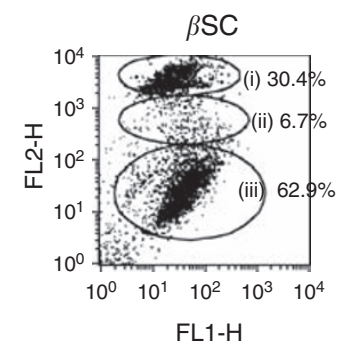

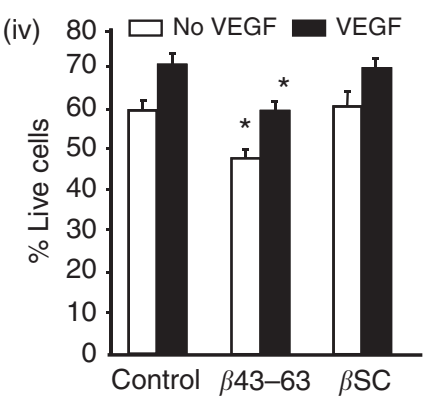

C

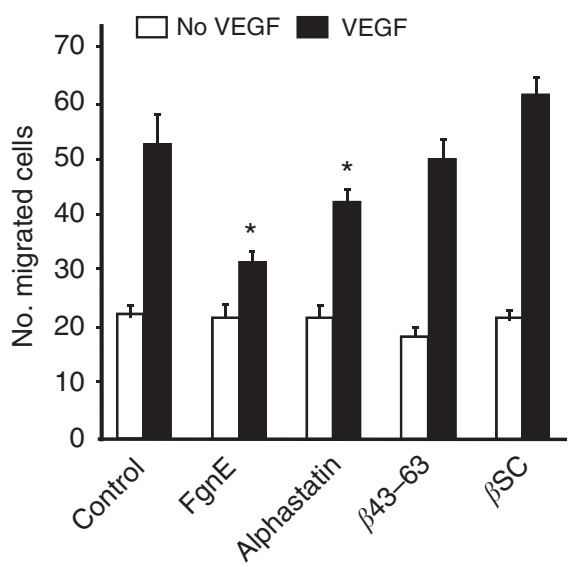

D

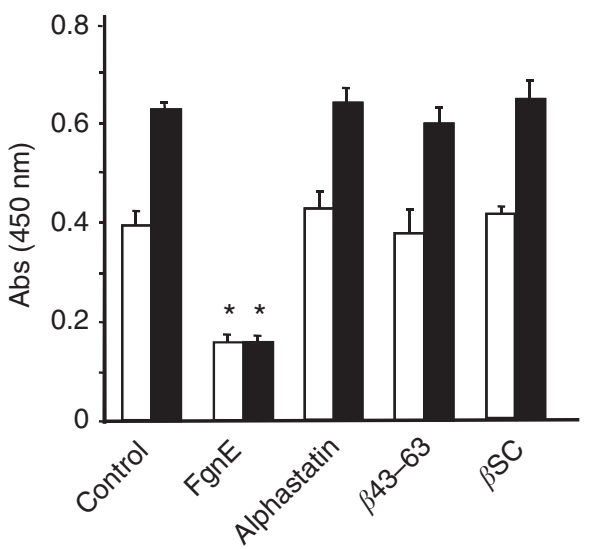

Figure 3 Effects of $\beta 43-63$ on $(\mathbf{A})$ viability, (B) Akt phosphorylation, (C) migration and (D) proliferation of HuDMECs in response to VEGF in vitro. All data are means \pm s.e.m. (A) Flow cytometry profiles showing (i) late stage apoptosis and necrosis (ii), apoptosis (iii) and live cells in control media or in the presence of $\beta 43-63$ or $\beta \mathrm{SC}$. (iv) graph showing \% live cells in presence or absence of VEGF in response to peptide treatment. (B) Western blot analysis of Akt phosphorylation in the presence or absence of VEGF ( $10 \mathrm{ng} \mathrm{ml}^{-1}$ ) in response to peptide treatment. (i) Scans of original blots for phosphorylated Akt and total Akt. (ii) Densitometry analysis showing slight inhibition in phosphorylation of Akt in the presence of VEGF (I0 ng ml ${ }^{-1}$ ) in response to $\beta 43-63$. (C) HuDMEC migration across a collagen-coated filter in response to medium alone (control) or medium containing IO ng ml ${ }^{-1}$ VEGF. (D) HuDMEC proliferation in response to medium alone (control or medium containing VEGF $\left(\mathrm{I} 0 \mathrm{ng} \mathrm{ml}^{-1}\right)$ ). *P $<0.05$ with respect to relevant control group. All data are the average of three repeat experiments.

inducing a marginal $(<10 \%)$ increase in late-stage apoptosis/ necrosis in VEGF-activated ECs. This effect was not seen when scrambled $\beta 43-63$ was used. To investigate whether this cytotoxic effect was mediated through the PI3K/Akt pathway, we undertook western blotting analysis of phosphorylated Akt. Although VEGF stimulated Akt phosphorylation, this was only marginally (nonsignificantly) inhibited by $\beta 43-63$ (Figure $3 \mathrm{~B}$ ) and unaffected by $\beta$ SC.

These findings suggested that the marked inhibitory effects of $\beta 43-63$ in the tubule formation assay (Figure 2) were not due to induction of extensive EC death. Moreover unlike FgnE and alphastatin, $\beta 43-63$ had no effect on either EC migration or proliferation (Figure $3 \mathrm{C}$ and $\mathrm{D}$ ), suggesting an alternative mechanism of action for $\beta 43-63$.

We then investigated whether $\beta 43-63$ might inhibit angiogenesis by inhibiting VEGF-activated adhesion of ECs to ECM proteins (an important step in the angiogenic pathway (Eliceiri, 2001)), namely collagen IV, fibronectin and vitronectin (Hynes, 2007; Mundel and Kalluri, 2007). Endothelial cells were preincubated with test peptides and VEGF for $1 \mathrm{~h}$, and then allowed to adhere for a further hour (Delaney et al, 2006). Whereas both FgnE and alphastatin significantly $(P<0.05)$ inhibited EC adhesion to collagen IV, $\beta 43-63$ significantly $(P<0.05)$ inhibited EC adhesion to all three ECM proteins. This effect was not seen with scrambled $\beta 43-63$ (Figure 4A).

Endothelial cells adhere to the ECM largely through cell-surface heparin sulphate proteoglycans and integrins and $\alpha_{\mathrm{v}} \beta_{3}$ is the only integrin to bind to all three of ECM proteins used here.
We therefore investigated whether $\beta 43-63$ might bind to heparin or $\alpha_{\mathrm{v}} \beta_{3}$ and thus block EC adhesion to the ECM. Activated EC were seen to adhere to $\beta 43-63$ in a manner that was significantly $(P<0.05)$ but not completely blocked by the addition of exogenous recombinant human $\alpha_{\mathrm{v}} \beta_{3}$, a noncovalent heterodimer containing the ligand binding extracellular portion of human $\alpha_{\mathrm{v}} \beta_{3}$ (Figure 4B). Moreover direct binding studies confirmed that recombinant $\alpha_{\mathrm{v}} \beta_{3}$ binds to vitronectin (a positive control) and $\beta 43-63$ in a solidphase assay (Figure $4 \mathrm{C}$ ). In contrast heparin did not significantly affect EC adhesion to $\beta 43-63$ (Figure 4B). To further investigate the possibility of $\beta 43-63$ mediating its effects by $\alpha_{\mathrm{v}} \beta_{3}$, we incubated $\beta 43-63$ with recombinant $\alpha_{\mathrm{v}} \beta_{3}$ before use in the Matrigel assay. In this experiment recombinant $\alpha_{\mathrm{v}} \beta_{3}$ alone had no effect on tubule formation, but completely ablated the $\beta 43-63$ inhibition of tubule formation (Figure 4D).

Finally, we investigated whether $\beta 43-63$ could inhibit tumour growth and angiogenesis in vivo using the CaNT murine mammary adenocarcinoma model. Control tumours grew steadily over the 10 -day injection period, whereas $\beta 43-63$ treated tumours showed nonsignificantly slower growth (being $16 \%$ smaller by day 10 ; Figure 5A). The experiment could not be extended beyond this point as the control tumours started to ulcerate and the mice had to be killed. $\beta 43-63$ injections were well tolerated in vivo with no significant effect on body weight or the general well being of the animals. A significant reduction in the number of vessels $(P<0.02)$ within the $\beta 43-63$ treated tumours was observed (Figure 5B and D). Moreover, a central area of necrosis was evident in both control and $\beta 43-63$ treated tumours, but 

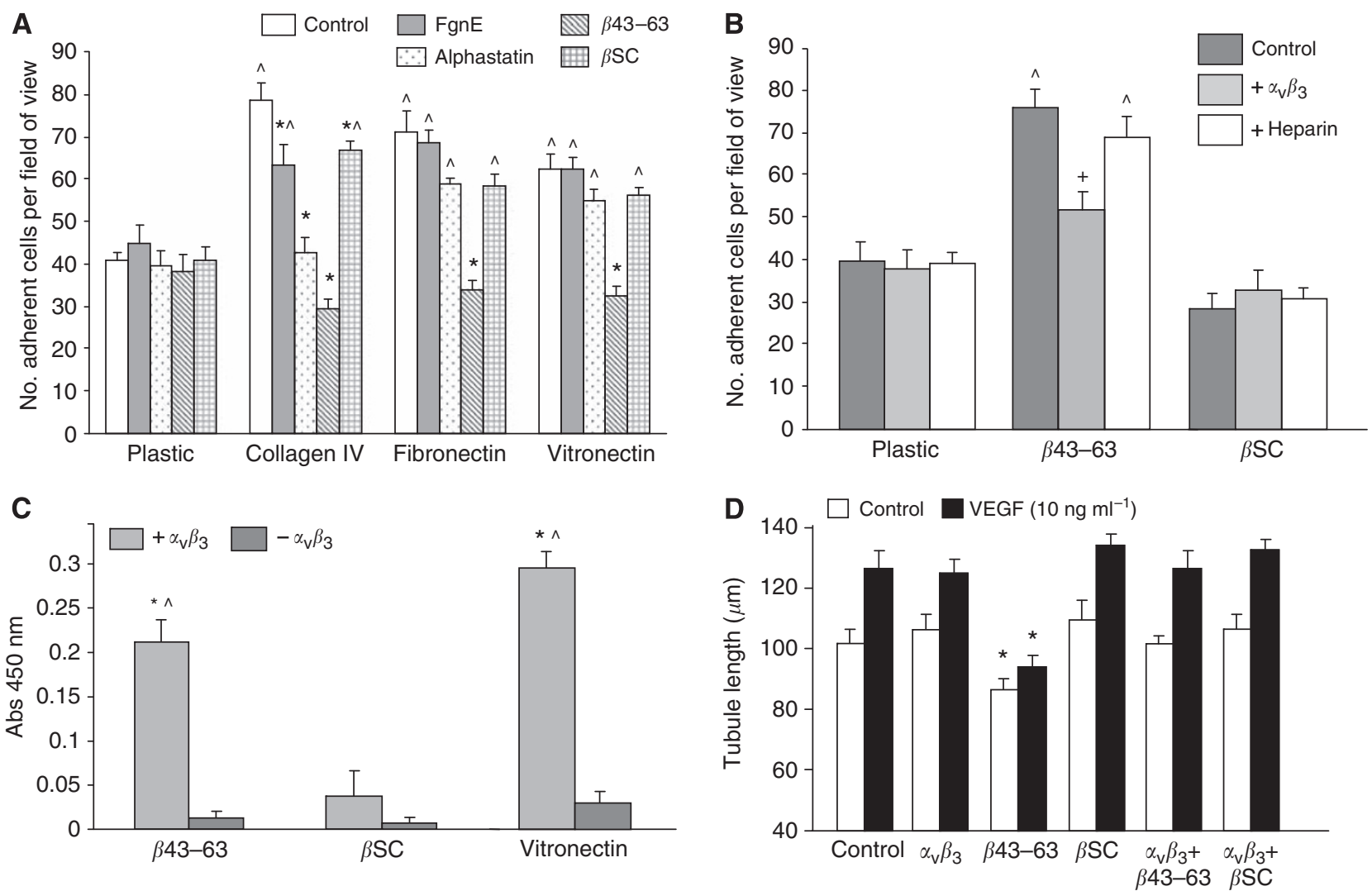

Figure $4 \beta 43-63$ markedly inhibits adhesion of activated human ECs to various extracellular matrix proteins in vitro: possibly by binding to $\alpha_{v} \beta_{3}$. (A) Effects of $\beta 43-63$ and related fibrinogen fragments on HuDMEC adhesion to three different ECM proteins. $\wedge p<0.05$ with respect to relevant plastic group. ${ }^{*} P<0.05$ with respect to relevant control group. (B) Effects of exogenous soluble $\alpha_{v} \beta_{3}$ or heparin on adhesion of HuDMECs to plates coated with $\beta 43-63$ or $\beta$ SC. $\wedge^{P}<0.05$ with respect to relative plastic group. ${ }^{+} P<0.05$ with respect to relevant control (untreated) group. (C) Direct binding of $\alpha \beta_{3}$ to $\beta 43-63, \beta \mathrm{SC}$ (negative control) or vitronectin (positive control) in a solid-phase assay. $* P<0.01$ with respect to $\beta$ SC negative control. $\wedge P<0.003$ with respect to- $\alpha_{v} \beta_{3}$ control. (D) Effects of pre-incubating $\beta 43-63$ or scrambled $\beta 43-63$ with recombinant $\alpha_{v} \beta_{3}$ before addition to the Matrigel assay. $* P<0.05$ with respect to relative control group. All data are means \pm s.e.m. Data are representative of three replicate experiments.

was significantly $(P<0.03)$ larger in $\beta 43-63$ treated mice (Figure $5 \mathrm{~B}$ and $\mathrm{C}$ ).

\section{DISCUSSION}

Complex interactions between microvascular ECs and factors in the local microenvironment (eg GFs, ECM constituents) regulate angiogenesis. In response to such signals, ECs degrade surrounding matrices, proliferate, migrate and fully differentiate to form new capillary tubules. In vitro models of these various steps are invaluable in gaining insights into the mode of action of newly identified angiogenesis regulators. We have used an array of such assays to fully characterise the anti-angiogenic effects of a peptide derived from human Fgn, $\beta 43-63$. We show that although $\beta 43-63$ inhibited EC differentiation as measured by tubule formation in response to multiple GFs, it had no effect on their migration or proliferation, and only a marginal effect on viability. It also inhibited the adhesion of VEGF-activated ECs to a number of angiogenesis-regulating ECM proteins - an effect involving blockade by the $\beta 43-63$ peptide of $\alpha_{\mathrm{v}} \beta_{3}$ on the surface of activated ECs.

Interestingly, although $\beta 43-63$ inhibited the effects of multiple GFs (VEGF, PDGF, HGF and FGF2) on ECs, it had much less of an effect on their activation by EGF. The overlapping signalling pathways used by VEGF, PDGF, HGF and FGF2 suggests that $\beta 43-$ 63 may inhibit ECs by the suppression of signalling molecules that are common to these four GFs, such as PI3K/Akt and/or FAK/
Paxillin (focal adhesion). Alteration of FAK/Paxillin association and phosphorylation by $\beta 43-63$ would be highly likely to result in reduced GF-induced migration (Saito et al, 2008) - an effect that was not seen with the peptide (Figure $3 \mathrm{~B}$ ). The marginal reduction in cell survival seen with $\beta 43-63$ (Figure $3 \mathrm{~A}$ ), and the minimal effect seen on Akt phosphorylation suggests that it also does not profoundly modulate the PI3K/Akt pathway in ECs (which is known to regulate EC survival and apoptosis (Kucharzewska et al, 2009)). Further studies are now warranted to identify the point of interaction between the signalling pathway activated by $\beta 43-63$ receptor binding and those activated by VEGF, PDGF, HGF and FGF2.

The fact that $\beta 43-63$ inhibited adhesion of VEGF-activated ECs to all three ECM proteins used suggests that this may represent at least part of the mechanism by which it inhibits tubule formation by VEGF-activated ECs (as GF-reduced Matrigel contains 30\% collagen IV; http://www.bdbiosciences.com). However, blocking of adhesion is unlikely to be the only mechanism involved as $\beta 43-63$ failed to inhibit migration of ECs across collagen type I or IV coated filters in our migration assays, and had a pro-apoptotic effect on VEGF-stimulated ECs in the absence of any ECM proteins.

Endothelial cells express a wide array of integrins that mediate their interaction with, and activation by, ECM components and GFs. Integrin $\alpha_{v} \beta_{3}$ is the only known integrin to bind to all three ECM proteins tested in our adhesion assays (Mizejewski, 1999; Rüegg and Mariotti, 2003), and moreover $\alpha_{\mathrm{v}} \beta_{3}$ is known to interact with the receptors for all the GFs tested and increases angiogenesis 

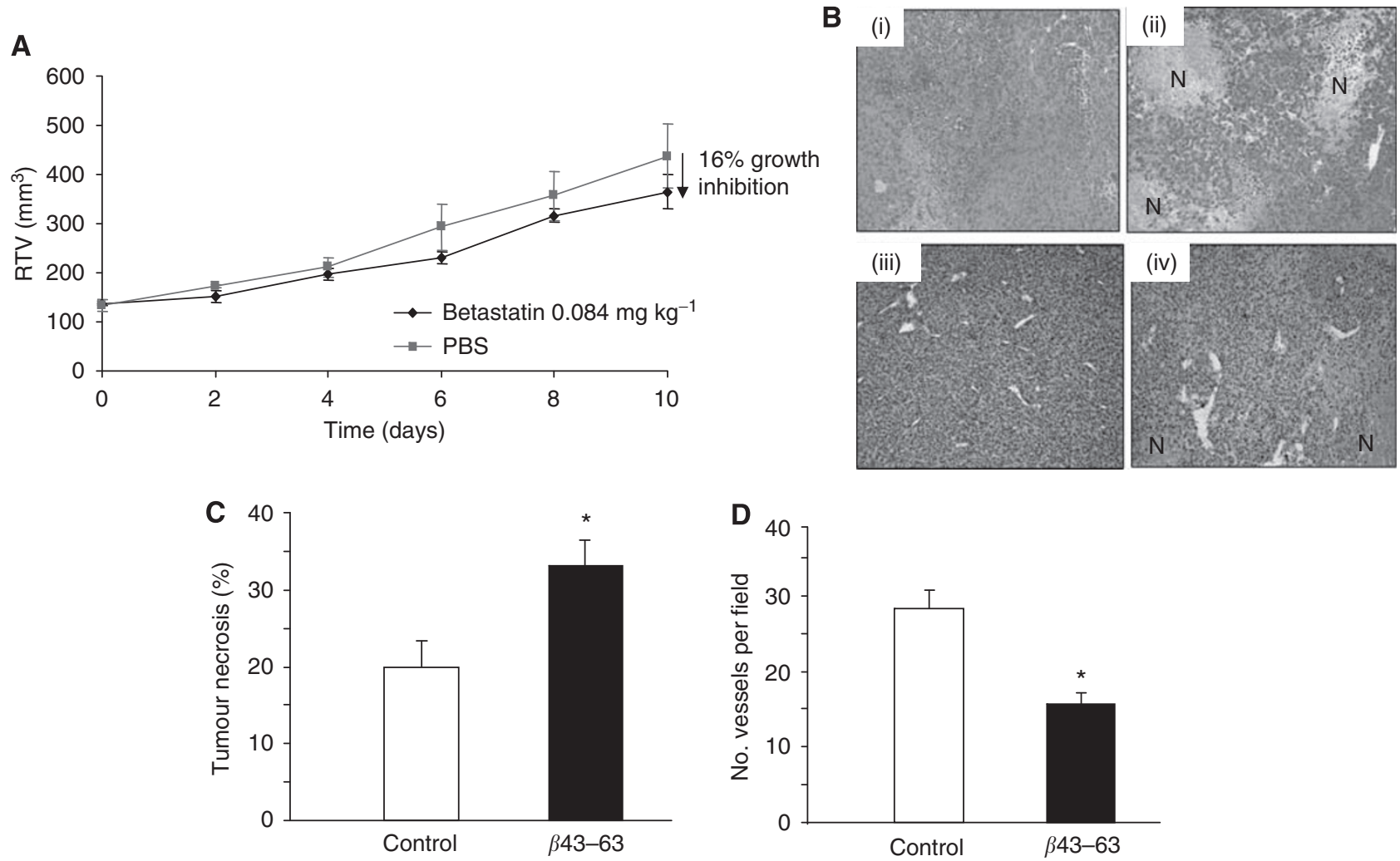

Figure 5 Effects of $\beta 43-63$ on CaNT mammary tumours in vivo: In vivo effects of $\beta 43-63$ on (A) the volume and (B) histological appearance of CaNT tumours grown in mice. Data are shown as mean \pm s.e.m. (B) Tumours were excised from control (i, iii) or $\beta 43-63$ treated (ii, iv) mice and general morphology/histology was examined at low magnification (i, ii) or stained with an anti-murine CD3I antibody and viewed at higher magnification (iii, iv). Cells in control tumours exhibited a compact regular morphology (i) with many small patent vessels in the viable regions lined with a continuous single layer of endothelial cells (iii). By contrast, $\beta 43-63$ treated tumours exhibited an irregular overall morphology with increased levels of necrosis ( $\mathrm{N}$; ii, iv) and relatively few large vessels in the viable regions (iv). Graphs showing $(\mathbf{C})$ percentage tumour necrosis and (D) CD3I vessel counts per field of view in tumours. All data are means \pm s.e.m. ${ }^{*} P<0.05$ with respect to control tumours.

when bound to ECM protein ligands (Soldi et al, 1999; Borges et al, 2000; Sahni and Francis, 2004; Kemp et al, 2006; Ellis et al, 2007). However, when soluble ligands bind/activate $\alpha_{v} \beta_{3}$, the ability of various GFs (eg VEGF, FGF2, PDGF and HGF) to activate their own receptors is inhibited; for example, interaction of soluble ligands with $\alpha_{\mathrm{v}} \beta_{3}$ can reduce VEGF-stimulated VEGF-R2 tyrosine phosphorylation (Soldi et al, 1999). Interestingly, although EGFR does bind to $\alpha_{\mathrm{v}} \beta_{3}$, activation of HuDMECs by EGF does not require the binding of $\alpha_{\mathrm{v}} \beta_{3}$ to EGFR (Ellis et al, 2007), which may explain why $\beta 43-63$ 's effects on EGF are more limited compared to the other GFs (ie where $\alpha_{\mathrm{v}} \beta_{3}$ binding to receptors is required for full activation; Borges et al, 2000). We therefore hypothesised that interaction of $\beta 43-63$ with $\alpha_{\mathrm{v}} \beta_{3}$ on the surface of ECs could explain its ability to inhibit multiple GF pathways stimulating EC differentiation. Moreover, some studies suggest that when $\alpha_{\mathrm{v}} \beta_{3}$ is occupied by a soluble ligand (such as $\beta 43-63$ ) it can mediate proapoptotic signals (Maeshima et al, 2001), which may explain the slight increase in apoptosis with $\beta 43-63$.

The $\alpha_{\mathrm{v}} \beta_{3}$ integrin is known to bind to the $\mathrm{RGD}^{572-574}$ sequence on the $\alpha$ chain of whole Fgn (Yokoyama et al, 1999). However, $\beta 43-63$ is derived from the $\beta$ rather than the $\alpha$ chain of Fgn, and does not contain an RGD or RGD-like sequence (Figure 1). It is now recognised that proteins and peptides can bind to $\alpha_{\mathrm{v}} \beta_{3}$ by non-RGD regions; for example, tumstatin, an inhibitor of tumour angiogenesis induces apoptosis of ECs by an $\alpha_{\mathrm{v}} \beta_{3}$ integrindependent manner (Maeshima et al, 2002), using non-RGD sequences (Maeshima et al, 2000), although $\beta 43-63$ bears no homology with the tumstatin $\alpha_{\mathrm{v}} \beta_{3}$ binding regions. Our experiments show recombinant $\alpha_{\mathrm{v}} \beta_{3}$ binds directly to $\beta 43-63$, partially inhibits the binding of HuDMEC to $\beta 43-63$, and incubation of recombinant $\alpha_{\mathrm{v}} \beta_{3}$ with $\beta 43-63$ before the Matrigel experiment ablates the ability of $\beta 43-63$ to inhibit EC differentiation/tubule formation. Therefore, taken together, our data suggest that one possible receptor for $\beta 43-63$ could be a non-RGD binding sequence on the $\alpha_{\mathrm{v}} \beta_{3}$ integrin.

Although studies investigating Fgn have shown that $\beta 43-57$ (contained within $\beta 43-63$ ) is a heparin binding site (Yakovlev et al, 2003), and heparin sulphate proteoglycans are used as coreceptors for the GFs (except EGF) (Neufeld et al, 1994; Chua et al, 2004; Kemp et al, 2006), binding studies have shown that the affinity of $\beta 43-57$ for heparin is relatively low compared to dimerised $\beta 15-66$ peptides (Yakovlev et al, 2003), suggesting that dimerisation is essential for high-affinity HS binding. As the $\beta 43-$ 63 peptide used in our study is not dimerised, it is unlikely that such binding would mediate the effects seen with $\beta 43-63$. Indeed our data show that heparin had no effect on the binding of HuDMECs to $\beta 43-63$ (Figure $4 \mathrm{~B}$ ) suggesting that heparin binding is not involved in mediating $\beta 43-63$ activity.

Interestingly, in contrast to FgnE and alphastatin that inhibit tumour growth by causing vascular damage and an increase in intravessel thrombosis within the tumours rather than by antiangiogenic mechanisms (Brown et al, 2002; Staton et al, 2004), $\beta 43-63$ caused a significant decrease in tumour vascularisation (ie was anti-angiogenic) without any evidence of thrombosis. This decrease in vessel counts could account for the increase in tumour necrosis, and decrease in tumour growth and suggests that should the control tumours not have ulcerated and therefore the experiment be continued beyond 10 days treatment, a greater 
effect on tumour growth would have been observed. The effects observed on blood vessels is similar to that reported using known $\alpha_{v} \beta_{3}$ antagonists (RGD-containing drugs) where vessel counts were reduced, but there were no observed effects on vascular thrombosis (Park et al, 2008), adding further evidence that $\alpha_{\mathrm{v}} \beta_{3}$ may be a receptor for $\beta 43-63$.

In sum, our data show for the first time that a novel, 20 -aminoacid peptide derived from the $\beta$ chain of human Fgn, has a unique ability to inhibit the angiogenic responses of ECs to multiple GFs such as VEGF, FGF2, PDGF and HGF in vitro, and to inhibit tumour vascularisation in vivo. This appears to involve, in part, the binding of $\beta 43-63$ to $\alpha_{\mathrm{v}} \beta_{3}$ integrin and the reduced ability of activated ECs to adhere to various ECM proteins. Further studies are now warranted to better understand the mode of action of this new agent so that its efficacy in anti-angiogenic therapies can be maximised.

\section{ACKNOWLEDGEMENTS}

We thank Professor Gillian Tozer and Fiona Morrow for their assistance with the animal studies and immunohistochemistry, respectively. CEL and CAS gratefully acknowledge the support of the Association for International Cancer Research for this study.

\section{REFERENCES}

Beckstead J (1994) A simple technique for preservation of fixation sensitive antigens in paraffin-embedded tissues. J Histochem Cytochem 42: 1127-1134 Bootle-Wilbraham CA, Tazzyman S, Marshall JM, Lewis CE (2000) Fibrinogen E-fragment inhibits the migration and tubule formation of human dermal microvascular endothelial cells in vitro. Cancer Res 60: 4719-4724

Borges E, Jan Y, Ruoslahti E (2000) Platelet derived growth factor receptor beta and vascular endothelial growth factor receptor 2 bind to the beta 3 integrin through its extracellular domain. J Biol Chem 275: 39867-39873

Brown NJ, Staton CA, Rodgers GR, Corke KP, Underwood JCE, Lewis CE (2002) Fibrinogen E-fragment selectively disrupts the vasculature and inhibits the growth of tumors in a synergic murine model. Br J Cancer 86: $1813-1816$

Chua CC, Rahimi N, Forsten-Williams K, Nugent MA (2004) Heparan sulfate proteoglycans function as receptors for fibroblast growth factor-2 activation of extracellular signal-regulated kinases 1 and 2. Circ Res 94: 316-323

Collingridge HAS, Chaplin DJ (2001) Proportion of infiltrating IgG binding immune cells predict for tumour hypoxia. Br J Cancer 84: 626-630

Daly ME, Makris A, Reed M, Lewis CE (2003) Hemostatic regulators of tumor angiogenesis: a source of antiangiogenic agents for cancer treatment? J Natl Cancer Inst 95: 660-673

Delaney CE, Weagant BT, Addison CL (2006) The inhibitory effects of endostatin on endothelial cells are modulated by extracellular matrix. Exp Cell Res 312: 2476-2489

Doolittle R (1981) Fibrinogen and fibrin. Sci Am 245: 92 - 101

Eliceiri BP (2001) Integrin and growth factor receptor crosstalk. Circ Res 89: $1104-1110$

Ellis IR, Schor AM, Schor SL (2007) EGF and TGF-alpha motogenic activities are mediated by the EGF receptor via distinct matrix-dependent mechanisms. Exp Cell Res 313: 732-741

Folkman J (1995) Angiogenesis in cancer, vascular, rheumatoid and other diseases. Nat Med 1: 27-31

Hynes RO (2007) Cell-matrix adhesion in vascular development. J Thromb Haemost 5: $32-40$

Kemp LE, Mulloy B, Gherardi E (2006) Signalling by HGF/SF and Met: the role of heparin sulphate co-receptors. Biochem Soc Trans 34: 414-417

Kleinman HK, McGarvey ML, Hassell JR, Star VL, Cannon FB, Laurie GW, Martin GR (1986) Basement membrane complexes with biological activity. Biochemistry 25: 312-318

Kucharzewska P, Welch JE, Svensson KJ, Belting M (2009) The polyamines regulate endothelial cell survival during hypoxic stress through PI3K/ AKT and MCL-1. Biochem Biophys Res Commun 380: 413-418

Maeshima Y, Colorado PC, Kalluri R (2000) Two RGD-independent alpha v beta 3 integrin binding sites on tumstatin regulate distinct anti-tumor properties. J Biol Chem 275: 23745-23750

Maeshima Y, Sudhakar A, Lively JC, Ueki K, Kharbanda S, Kahn CR, Sonenberg N, Hynes RO, Kalluri R (2002) Tumstatin, an endothelial cellspecific inhibitor of protein synthesis. Science 295: 140-143

Maeshima Y, Yerramalla UL, Dhanabal M, Holthaus KA, Barbashov S, Kharbanda S, Reimer C, Manfredi M, Dickerson WM, Kalluri R (2001) Extracellular matrix-derived peptide binds to alpha(v)beta(3) integrin and inhibits angiogenesis. J Biol Chem 276: 31959-31968

Malinda KM, Ponce L, Kleinman HK, Shackelton LM, Millis AJ (1999) Gp38k, a protein synthesized by vascular smooth muscle cells. Exp Cell Res 250: $168-173$

Mizejewski GJ (1999) Role of integrins in cancer: survey of expression patterns. Proc Soc Exp Biol Med 222: 124-138

Mundel TM, Kalluri R (2007) Type IV collagen-derived angiogenesis inhibitors. Microvasc Res 74: 85-89

Neufeld G, Tessler S, Gitay-Goren H, Cohen T, Levi BZ (1994) Vascular endothelial growth factor and its receptors. Prog Growth Factor Res 5: 89-97

Park K, Kim YS, Lee GY, Park RW, Kim IS, Byun Y (2008) Tumour endothelial targeted cyclic RGD-modified heparin derivative: inhibition of angiogenesis and tumour growth. Pharm Res 25: 2786-2798

Rüegg C, Mariotti A (2003) Vascular integrins: pleiotropic adhesion and signaling molecules in vascular homeostasis and angiogenesis. Cell $\mathrm{Mol}$ Life Sci 60: $1135-1157$

Sahni A, Francis CW (2004) Stimulation of endothelial cell proliferation by FGF-2 in the presence of fibrinogen requires alphavbeta3. Blood 104: $3635-3641$

Saito Y, Shiota Y, Nishisaka M, Owaki T, Shimamura M, Fukai F (2008) Inhibition of angiogenesis by a tenascin-c peptide which is capable of activating betal-integrins. Biol Pharm Bull 31: 1003-1007

Soldi R, Mitola S, Strasly M, Defilippi P, Tarone G, Bussolino F (1999) Role of alphavbeta3 integrin in the activation of vascular endothelial growth factor receptor 2. EMBO J 18: $882-892$

Staton CA, Brown NJ, Rodgers GR, Corke KP, Tazzyman S, Underwood JC, Lewis CE (2004) Alphastatin, a 24-amino acid fragment of human fibrinogen, is a potent new inhibitor of activated endothelial cells in vitro and in vivo. Blood 103: $601-606$

Yakovlev S, Gorlatov S, Ingham K, Medved L (2003) Interaction of fibrin(ogen) with heparin: further characterization and localization of the heparin binding site. Biochemistry 42: 709-716

Yokoyama K, Zhang XP, Medved L, Takada Y (1999) Specific binding of integrin alpha $\mathrm{v}$ beta 3 to the fibrinogen gamma and alpha $\mathrm{E}$ chain $\mathrm{C}$ terminal domains. Biochemistry 38: $5872-5877$

Zacharski LR, Memoli VA, Rousseau SM (1986) Coagulation-cancer interaction in situ in renal cell carcinoma. Blood 68: 394-399 